\title{
ARTE Y FILOSOFÍA. SIGNOS DE SU ACTUAL PERMUTACIÓN RECÍPROCA
}

\section{EDGARDO ALBIZU \\ USAL-UNGSM}

\section{Introducción}

Una característica de nuestro presente espiritual es el aparente agotamiento de la capacidad de significar, definitoria de arte y filosofía. Desde un punto de vista trascendental ambos pueden ser considerados sistemas de significancia, el núcleo de cuyo ejercicio es la libertad poiética, en un caso radicalizante de modalizaciones sensoriales y en otro de los incrementos conceptuales, mas ello de modo tal que arte es conceptuación sensorial y filosofía sensificación conceptual. Dicho de otro modo: arte consiste en construir sistemas de significado con la superficie sensorial del mundo, de ninguna manera reducida a lo sensual: las construcciones de Mondrian o Escher son formas de operatividad de dicha superficie. Filosofía, por su parte, es hacer contextos sensoriables mediante el interrogar que transgrede y supera los límites conceptuales vigentes de antemano: aún el sensualismo es trans-sensorial y conceptual.

Salta a la vista el actual agotamiento de esa capacidad significante de arte y filosofía. En ambos dominios la espontaneidad inventora de posibilidades va siendo sustituida por una habilidad para repetir, incluso por un virtuosismo para variar, del que está ausente aquel momento creador subrayado por Kant: dar las reglas al arte; agregamos: también a la filosofía. $\mathrm{El}$ arte ha sido "touché", puede decirse con una fórmula usada por Mallarmé respecto del verso. La saturación de significante y significado, alcanzada por el romanticismo, desencadena las nuevas búsquedas formales que impulsan al arte durante casi dos siglos. Esa etapa comenzó a declinar hace algunas décadas. O la tarea de crear arte es demasiado "titánica" para los actuales artistas, o bien las posibilidades de significar están exhaustas en ellas mismas. Otro tanto cabría decir de la filosofía: o cumbres problemáticas demasiado altas, inaccesibles a los filósofos, o incapacidad de éstos para enfrentarse a las tareas por lo demás siempre propias del oficio.

No es fácil resolver el dilema. Diagnósticos epocales y culturales permanecen en la periferia del problema. Aún menos efectivas resultan las recomendaciones pedagógicas y las correcciones metodológicas que 
pudieran señalarse. Sin embargo, no hay razón para considerar un mal a la situación aludida. Ante ella lo que cabe es conocerla y no intentar lo imposible: reformarla.

El rasgo específicamente intelectual de dicha situación se manifiesta, en la filosofía, en tanto paulatinamente se afianza en ella el dominio de la crítica sobre otras formas sistémico-constructivas del pensar. Así vista la crítica implica (1) constitución de diversos campos de cumplimiento de la libertad interrogante (p.e. metafísica, epistemología, ética); (2) paralela concentración de la libertad, no encapsulada en los campos antes señalados, en un reducto primordial, consistente en analizar, juzgar, aceptar o condenar productos surgidos de aquellos campos: ésta es la cumbre crítica cuya condición material de posibilidad se reduce a los productos antes mencionados.

La capacidad de juzgar, propia de la filosofía (2), tiene como objeto exclusivo lo producido en (1): se juzga sí lo allí establecido, construido, proyectado, se corresponde con los modelos que (2) construye e interpreta; sobre todo si lo producido se halla a la altura de lo proyectado. Se puede así comprender que la causa final de la crítica es la legitimación: el sello de legitimidad procede de haber aprobado el examen crítico. Otras consecuencias suponen la legitimación como meta positiva del análisis racional. En concordancia con esto, la actividad desarrollada en los diversos campos filosóficos (1) se concentra en producir el "material" sobre el cual ha de ejercerse la crítica (2). En primera instancia, el trabajo filosófico consiste, pues, en producir material para el análisis legitimante: (1) produce y (2) legitima. Enseguida se genera la sospecha de que pueda tratarse de un círculo vicioso, debido a que ambos momentos se condicionan recíprocamente. Ante tal sospecha cabe observar que, por cierto, se trata de un círculo, en el cual se cifra buena parte de la historia interna de la filosofía. Por otra parte, no es formalmente un circulo vicioso, en la medida en que tanto (1) como (2) son en verdad incrementos irregulares, siempre tendientes a cero (entropía completa). Si en (1) y (2) incremento $=0$, entonces, y solo entonces, se tiene un circulo vicioso. De lo contrario, no cabe tal fórmula. Antes bien, se puede hablar de incremento dialéctico, lo cual ratifica la sospecha de que (1) y (2) actúan respectivamente como siervo y amo. En la situación actual el siervo está viejo, esclerótico y exhausto, en tanto el amo tiende a una megalomanía cada vez más excéntrica, exaltada y alambicada. La crítica es el amo, de facto dependiente de las capacidades de los siervos productores y siempre afianzado mediante el ensayo de todas sus 
posibilidades de análisis. En tanto (1) tiende a cero, (2) se estira desplegándose desde sí mismo. Dicho estiramiento es la hipercrítica, cuyo ejemplo filosófico más característico es la que Marx llamó "crítica crítica" de la izquierda hegeliana. En nuestros días el caso principal de esa "crítica crítica" filosófica se centra en el concepto de deconstrucción, que amontona la tarea filosófica en una gama que abarca desde el desmontaje analítico hasta la destrucción lisa y llana.

La deconstrucción se ha mostrado como núcleo de la actual crítica filosófica. En la actualidad pretende concentrar la esencia de la filosofía pues, según señala Heidegger en el $\ 6$ de Sein und Zeit, se trata de liberar las experiencias que producen obras filosóficas. Heidegger habla de una "destrucción del contenido transmitido de la ontología antigua, en dirección a las experiencias originarias en las cuales se obtuvieron las primeras determinaciones del ser, conducentes desde entonces” (SZ 22). Así, pues, se trata de liberar experiencias productoras de obras filosóficas. Pero esto no logra una crítica solo crítica, reductora de (2) a mero rechazo de (1), sino una crítica a la vez autocrítica del pensar, incluso en tanto preproductor de productos filosóficos. Tal lo que buscó Heidegger, quien de esa manera garantizó vida a la pura filosofía, vida sin duda dependiente de (1), si bien no del todo, pues su ejercicio acota el protorrecinto filosófico: las experiencias originantes de conceptos. Sin embargo, incluso así presentado, el recinto no deja de ser artificialmente restringido, pues las experiencias, en especial las generadoras de filosofía, no son ahora cerradas y completas sino presentes primarios inacabados, cuyo ser-experiencia se cifra en desplegarse desde sí hacia sí a partir de la irrupción de futuro que constituye el nacimiento de la experiencia en cuanto tal, irrupción que es, por ende, ella misma, fórmula con la que se piensa su libre autotrascenderse poiético-conceptual interno: toda experiencia es una libertad especulativa naciente y en desarrollo.

Se tiene así un indicio de que la deconstrucción es una retirada. Para que no se convierta en huida caótica, en desbandada, conviene equilibrarla con la idea de "profundidad conceptual", introducida por Rescher para explicar la infinitud de tareas de la ciencia natural, aún cuando su dominio objetivo sea finito (cfr. LC 75). Dicha "profundidad" es también propia de arte y filosofía: ésta es su inventora y administradora, por lo que, para poderse desplegar como tal (2), ha menester de sustrato precrítico (1). El ente puede ser analizado, desmontado y destruido de muchas maneras, mas nunca de modo que se supere el repertorio finito de posibilidades, o su ser en tanto pensable. De vez en cuando la profundidad conceptual necesita 
un refuerzo operativo procedente del nivel (1): efectivo incremento siempre finito, de su material. Falta de tal refuerzo, la filosofía (2) comienza a debilitarse, según ocurre desde hace algunas décadas.

Si pudo decirse del verso que fue "touche", cabe ahora decir lo mismo del pensar filosófico en cualquiera de sus formas: análisis lógico, intuición fenomenológica, síntesis especulativa, hermenéutica deconstructiva, e incluso de su nuclear poiesis de tiempo. En cada una de sus regiones temáticas y de sus tendencias operativas, la filosofía mengua, se adelgaza hasta confundirse con la "causerie" más o menos frívola acerca de lo que no requiere tomar decisiones urgentes. El choque con la in-significancia le desquicia los aparatos formales de presentación, y su alianza con el lenguaje se disuelve tan pronto como repara en que éste no saca al pensar del relativismo sino que, al contrario, lo sumerge en él. Caídos los propios dioses, cada filósofo la emprende contra los dioses de los otros. La atmósfera respirada por la actual filosofía languideciente resulta así un híbrido de morgue y parlamento. En ella el lenguaje se reduce a cotorreo, hablar por hablar, según el democrático imperativo hipotético: "si nada hay de que hablar, habla entonces sin ton ni son a fin de disimular la falta de substancia". A los idola theatri, agudo hallazgo del canciller Bacon, con el que culmina su diagnóstico de la génesis del error, ha llegado la hora de agregarles los idola sepulcri, dominantes en nuestro actual filosofar. El foro filosófico presenta cada vez más el aspecto de un diálogo entre tradiciones difuntas y obediencias retrospectivas, en el que se trata de ser según algún cruce de herencias, incluso descontinuadas y deconstruidas. Ser "es" herencias, aceptadas o despreciadas. En tal espacio los más convencidos son los legos: artistas opinantes y filósofos "conversantes", lanzados a sustituir la poiesis por información y comunicación. No obstante, la plebeya reducción prosaica de la in-significancia no se limita a las tonterías hechas y dichas por "artistas" y "filósofos". (Siempre las han cultivado con mayor o menor suficiencia). Se trata de algo más grave, de una verdadera "enfermedad mortal", ya diagnosticada por Hegel y Nietzsche: la reducción de arte y filosofía a objetos culturales; la museización, espectacularización, seminarización y congresificación de la libertad, que sólo es salto creador de poiesis, theoria y praxis.

Lo dicho equivale a afirmar que arte y filosofía pueden estar enfermos. Cabe, pues, preguntar cómo puedan enfermarse los sistemas de significancia. ¿Qué se enferma en verdad? No dichos sistemas, pues no les es inherente la enfermabilidad, como tampoco lo es a los números ni a los 
fenómenos inorgánicos. Es enfermable lo viviente; sobre todo el que es como existente y se condensa en torno del centro conciencia. (La existencia incluye las incógnitas de lo inconsciente y los lenguajes. La conciencia es inexistencia in-inconsciente y antilenguaje, ejercidos como configuración del existir. Arte y filosofía son sistemas trascendentales de la conciencia, configuradores, pues, del existir). Se enferma el Dabewusstsein, el conscienteestar-siendo. Su enfermedad consiste en el bloqueo de la existencia consciente para la vida, así como el sueño consiste en el bloqueo de la existencia viviente para la conciencia. La "enfermedad" del arte y la filosofía es, según esto, un bloqueo de la mónada existencial-consciente para la vida, que es autopoiésis autoteórica (autocontemplante) en cuantos grados diferenciales se puedan encontrar en ella. Vida, existencia y conciencia se bloquean entre sí de diferentes maneras y grados. La mónada cerrada en sí, que deja fuera su plenitud (libertad o salto creador) es lo enfermo, aquello cuya enfermedad contamina a la filosofía y al arte. La existencia cierra su franquía a la conciencia y se regodea en sus aperturas hipercontingentes: pathos, opinión, temples de ánimo, represiones y condensaciones. La conciencia, por su parte, cierra también su franquía al existir (olvida mirar "hacia abajo") y se atrinchera en sus aperturas "sublimes": cultura, derecho, valores.

Si se trata de patologías de arte y filosofía, cabe reconocer que con ellas apuntan fenómenos habitualmente imperceptibles. Cierta gama de lo enfermable del consciente-estar-siendo pone de manifiesto rasgos esenciales de arte y filosofía, de otro modo inaccesibles e insospechados, lo que puede explicar por qué permanecieron ignorados hasta hace poco tiempo. Son descubrimientos filosóficos acerca del arte. Son los fenómenos ocasionalidad, apertura e in-significancia.

\section{Márgenes de la conciencia estética: ocasionalidad, apertura, in- significancia}

El bloqueo de la conciencia para la existencia encapsula su omnitemporalidad en el instante propicio; la condensa en cada ocasión, en Kairós. El bloqueo de la existencia para la conciencia libra su temporalidad a su propia índole, abierta a la extinción: Cronos, que genera y también devora a sus criaturas. Por fin, el bloqueo de existencia-y-conciencia para sus tiempos (extinción y ocasión) sustrae el tiempo que son, que así se designifica, de modo que Aion sólo es presente por ausencia. Se tiene así la génesis de los tres fenómenos antes señalados. 
La ocasionalidad fue teorizada por Gadamer hacia 1960. A pesar de que este autor no la coloca en el primer plano de su análisis de la experiencia del arte, surge como uno de sus descubrimientos centrales. En efecto, Gadamer expone el "fundamento ontológico de lo ocasional y lo decorativo". Por ocasionalidad entiende "que el significado se determina, en cuanto al contenido, desde la oportunidad en que es pensado, de modo tal que contiene más que si careciese de esta oportunidad" (WM 137). El sentido de tal idea se capta a partir del esfuerzo por trascender la dimensión estética, que a su vez supone abandonar la subjetivación de dicho corpus filosófico, resultado -según Gadamer- de la filosofía de Kant. Una tarea principal de la hermenéutica filosófica del arte se cifra, pues, en retomar la pregunta por la verdad del mismo, cuyo prerequisito primario consiste en hacer visible "la abstracción de la conciencia estética"(WM 84). Sólo así será posible fundamentar la tesis según la cual la experiencia del arte es un modo de conocimiento de especial índole, sin duda distinto del científico, el ético, el conceptual, pero de todos modos conocimiento, o sea un modo de proporcionar verdad (WM 93). Para lograrlo Gadamer diseña una ontología de la obra de arte cuyo momento inicial es el análisis del concepto juego en tanto mundo cerrado, englobante de todos los jugadores. Ahora bien: el juego humano encuentra su culminación en y como arte. Tal proceso culminatorio es lo que el autor llama transformación en imagen (WM 105 ss.), presidida por la "no-diferenciación estética" (WM 111); en tal sentido: in-diferencia.

Así recuperado, lo estético muestra una temporalidad de especial índole: sin-tempidad, Zeitlosigkeit, no confundible con la intemporalidad metafísica, o Unzeitlichkeit (WM 115). La que probablemente pueda ser considerada cumbre de esta hermenéutica filosófica es, por tanto, una teoría del singular tiempo de la obra de arte, en modo alguno identificable con el histórico-existencial, pues hay en él una simultaneidad, incluso una contemporaneidad (Gleichzeitigkeit. igual temporabilidad) que lo hace afín a la perpetración religiosa, con sus imperturbables ciclos, que cada vez se inserta de nuevo en la historia pero sin ser contenida por ella, de modo que es coherente considerar a la obra como "incremento en ser" (WM 133).

En este análisis "ocasionalidad" aparece como un concepto primario, prístino, límpido y, como tal, "inocente". Eso resultaría del análisis fenomenológico. Sin embargo, tal carácter originario en modo alguno significa la ingenuidad de un modo singular de relación de la obra de arte con el real tiempo histórico, modo asimilable a la caída platónica. La 
fenomenología no consiste en describir ideas puras, en su incontaminada pre-experiencialidad. No pretende ser ideo-logía, sobre todo porque las ideas terminan por ser demasiado terrenales. La conciencia fenomenológicamente depurada se enfrenta con la experiencia del lenguaje (que es el lenguaje), de modo que la $W$ esenschau consiste en ver el concepto, el ente, en el lenguaje. Por el hecho de ser-en-el-lenguaje (en uno o más idiomas), veo más que lo que veo y, a la vez, veo menos que lo que veo. El lenguaje sabe más y menos que yo, que la unidad de la significancia. Por eso resiste a las epojés, si cabe incluso con desafíos y astucias.

Tal dialéctica intra-intuitiva -tal tormenta interior a la transparencia de la intuición esencial- tiene uno de sus ejemplos más nítidos en el concepto estético-hermenéutico de ocasionalidad. En efecto, occasio es el tiempo propicio, el momento favorable, la oportunidad. Ocasionalidad de la obra de arte quiere decir, pues, desde la experiencia del lenguaje, que la obra es en su oportunidad, con la cual mantiene una dialéctica de mutuo incremento. Cuanto más propicia es la oportunidad, más aparece la obra en lo que le es favorable, y viceversa: cuanto más favorable hay en ella para su presencia, más oportuna y propicia es la ocasión para recibirla. Kairós ingresa así a título de arquetipo mítico -y mito-lógico- de la obra de arte. La metafísica prolonga ese motivo no sólo en la concepción ocasionalista Dios causa eficiente en cada causación ocasional, por ejemplo en Malebranche- sino en la verdad divina -el supra-ser de Dios- como ahora (nun) que contiene y anula todo tiempo, como en Meister Eckhart. Se está así ante la nada paradójica conclusión según la cual el puro residuo fenomenológico ocasionalidad hace posible des-purificar, desublimar, la experiencia del arte. Cuando la pureza ocasional de la obra la lleva hasta la orilla de este Cocytus, se está ante síntomas de otros tiempos. "Ocasionalidad", con su peso conceptual en Kairós, indica que la obra de arte es tal conglomerado de tiempo que parece ahogarse, por lo cual necesita absorber la ocasión real.

El segundo de los fenómenos señalados fue también expuesto por primera vez hacia 1960. Se trata de la apertura, según la presenta Umberto Eco en Opera Aperta. Si bien la inspiración proviene de la música contemporánea, el fenómeno descubierto a través de ella concierne a todas las artes según se dan en nuestro presente. $\mathrm{El}$ autor sostiene que las obras creadas hasta nuestra época se caracterizan por el acabamiento estructural, aun cuando dejen abierta la posibilidad de reinterpretación, posibilidad insita en todo arte. Lo novedoso que ahora ocurre es la aparición de obras no 
acabadas, no por falla o defecto, sino por ser ése su modo de ser. "El arte contemporáneo se ve en la necesidad de contar con el Desorden" (OA 46). Ya no domina una concepción preformada de arte sino que "de hecho se va delineando en nuestra cultura un concepto de arte distinto de los precedentes". En éste el rasgo básico es la apertura constitucional de las obras, llevadas a su término por el intérprete en el mismo momento en que las goza estéticamente.

La apertura no tiene, pues, la misma dirección constitutiva que la ocasionalidad. Mientras ésta trae consigo el aflorar de una exigencia de hipercompletez de la obra en sí perfecta y acabada, que la impulsa a hacer artístico el ahora real, a sublimar el instante fugaz, la apertura de la obra significa que ella no ha alcanzado aun el acabamiento mínimo que la sublime en un tiempo propio, capaz a su vez de henchir el ahora, de conferirle fugaz eternidad, sino que ella es un proyecto lanzado a la realidad, en espera del artista que la ocasionalice tan pronto como sea posible. Su ocasionalidad es entonces terrenamente trabajosa. "El autor parece entregar (estas obras no acabadas, E.A.) al intérprete más o menos como las piezas de un mecano, desinteresándose aparentemente de adónde irán a parar las cosas" (OA 66).

"Apertura", por ende, hace visible, en este contexto, una fisura de "terrenalidad" de la obra. Eco la interpreta desde la teoría de la información como una actividad que es pura poiesis del lenguaje, a diferencia de la fenomenología, en la cual la conciencia consuma una polémica con aquél. El aspecto que Eco rescata de la teoría de la información es más bien la performatividad o espontaneidad de los sistemas semióticos: el artista "introduce módulos de desorden organizado en el interior de un sistema para aumentar su posibilidad de información" (OA 139). Y si la ocasionalidad de la obra conduce, según se vio, a condensarla como incremento en ser, su apertura le hace posible consumarla como "contemplación del orden reencontrado" (OA 162).

Sin embargo, ni ocasionalidad ni apertura llevan hasta su último extremo la conceptuación de la gloria de la obra de arte y de aquello que, en esa misma explosión, falta o se sustrae: el indicio de una gloria faltante. En tal punto se percibe cuanto implica la filosofía en la totalidad de sus dimensiones -en este caso, en su ausencia, aun e incluso por ella- para concebir el fenómeno, pues en ambos descubrimientos de punta ocasionalidad y apertura - falta el horizonte de sentido que proporciona la idea de la filosofía como metasistema (sistema de sistemas), rasgo que no sólo asume la culminación hegeliana sino también la gigantomaquia 
posthegeliana. En efecto, ni la hermenéutica ni la semiología tienen la posibilidad de aprehender por sí mismas las metamorfosis de ser y sus horizontes. En consecuencia, es aun insuficiente concebir a la obra como sublimación ocasional de lo real, o como caída en este medio, lo que supone encontrar un orden nunca del todo perdido mas sólo experimentable en tanto caído. Es necesario que la obra se muestre, en una experiencia metadeconstructiva, como sistema modal de significancia o modalizador sensorial de lo pensante y ente, como inteligidora de ser hasta la negatividad del mismo ser.

La obra de arte es sistema de signos y superación de la semiosis en la prehensión (en el sentido que le da Whitehead) de sus propios límites. ( $\mathrm{Si}$ se considera lo primero, entonces la crítica de Gadamer a toda teoría semiótica del arte resulta justificada; si, en cambio, también se tiene en cuenta lo segundo, dicha crítica resulta superflua e incluso superficial.) Si hace setenta años se pudo decir que la época de los sistemas había pasado (Heidegger), ahora cabe señalar la vigencia cada vez mayor de la necesidad de proyectar sus posibilidades implícitas, no tanto como clave de teorías ya cumplidas, sino más bien como forma descubridora de lo pensable en lo pensado. Cuenta ahora el sistema individuado, en este caso por la poiesis destinada a los sentidos, al concepto que es lo visible, lo audible, etc.

La poiesis supone las complicaciones y limitaciones de la ocasionalidad y la apertura en los cuatro estratos de significancia de la obra de arte, estratos dialécticamente entrelazados como urdimbre genética conceptual, que tanto más se abre y ocasionaliza cuanto más integrada está, lo que por su parte implica su cada vez más denso entretejerse con la trama de los comportamientos estéticos. Sólo así es posible construir el morfograma formal de la obra de arte sin idealizarla, historizarla (tradicionarla o diferenciarla), semiotizarla o destruirla. La que puede llamarse "estética de trama" fue expuesta por Luis Juan Guerrero en su libro: Estética operatoria en sus tres direcciones (1956-67), tres volúmenes. En cuanto a la estética de urdimbre, vengo esbozándola desde alrededor de 1970; la he expuesto de manera sistemática pero incompleta en mi libro: Verdades del arte (2000). Trama y urdimbre son sistemas de sistemas, confluyentes en una cumbre de exhaución: la apertura de la urdimbre tras la integración de significados universales (metafísicos, simbólicos, etc.) en la plena realidad de las formas. En cuanto al significante, dicha apertura se cifra en las nuevas búsquedas formales; respecto del significado implica que se da a pensar el tiempo en tanto verdad del ser, que sobrepasa toda 
posibilidad de significar. Por eso el tiempo es siempre "más-en-significado" $\mathrm{y}$, por eso, significado in-significante. La in-significancia es, por ende, la verdad de lo ocasional y abierto. Ni el fugaz Kairós ni el grávido Aion agotan el tiempo, siempre tendiente a Kronos. La obra, ocasionalmente lograda como espontánea apertura reveladora, no llega a consumar la modalización del tiempo como absoluto. De tal manera la obra de arte es señal o indicio del tiempo, que lo pone de manifiesto en momentos propicios para el sistema de significancia (trama y urdimbre) y sus limitaciones. En su significarse el tiempo se sustrae, aun al arte, y a este de manera harto punzante. No hay significante que lo abarque: se limita a retenerlo en tanto lo aleja. En y por su grandeza es, pues, in-significante: pequeño e insuficiente, como toda in-significancia, y asimismo como toda plenitud.

\section{La triple (retro) epifanía artística del tiempo (ocasionalidad, apertura, in-significancia) como experiencia metafísica generante.}

Se han presentado tres fenómenos, cada uno de los cuales ejerce una doble conexión constitutiva: 1) trascendental, entre dos sistemas normales de significancia: arte y filosofía, por lo cual son la cifra de permutación metafísica originaria; 2) transversal, entre plexos de la significancia trascendental y estructuras de la existencialidad. A la vez que síntomas de fusiones de significancias diversas, ocasionalidad, apertura e insignificancia indican y proyectan desplazamientos histórico existenciales transmodernos por los que arte y filosofía puedan liberarse de una secular servidumbre babilónica a sistemas culturales alienados.

La ocasionalidad de la obra de arte muestra que ella es tan tiempo (Kairós) que cada vez que es -ser en síncopas, o ser discreto- necesita todo el tiempo real resumido en un ahora estable. La estructura trascendental de la ocasionalidad se cifra en una fisura en el ente, de modo que el encuentro de ambos mundos -el eterno retorno inmanente de la obra y la extensión extática del existir- es tanto más aleatorio cuanto más ambos mundos son por la necesidad de tal encuentro. El protoconcepto negativo de la metafísica es, según esto, la paradoja de que lo necesario es aleatorio y viceversa.

La apertura de la obra de arte muestra que ella descubre dentro de sí posibilidades ontológicas tanto más cuanto ella es, en su tiempo inmanente, sin terminación, sin fin. La terminación se halla en otro plano respecto de la obra tal como es ahora. Su propio ser no es uno, homogéneo: 
parece roto. Toda obra, en tanto abierta -las cerradas pueden ser abiertas por transgresión violenta, y eso es aquí lo decisivo-, es tan frágil e incompleta que cada vez que es necesita elementos reales ajenos a ella para retener su ser. Este se halla en un constante ausentarse, por lo que la obra de arte se "desaísla"(respecto de su "insularidad") y parece acompañar más de cerca al hombre en su destino histórico. De rebote esto la perfila cada vez en mayor lejanía respecto de "lo humano", "lo vital", "lo cultural", para quedarse con la in-significancia acentuada como el Cronos que se nutre con sus absolutos. El protoconcepto negativo de la metafísica asume ahora nueva forma: la paradoja de la cercanía de lo lejano y viceversa.

La in-significancia es el fenómeno de que la obra de arte es tan plena que cada vez que es desborda su ser, su tiempo, su novedad. Es tan plena que es des-siéndose, de-sintiéndose. De tal manera es el acaecer unitario del protofenómeno de toda theoría: cada uno sabe más que lo que actual y conscientemente sabe, razón por la cual puede configurarse el desequilibrio inverso: ahora sé menos de lo que realmente sé. Esta es le tercera paradoja protoconceptual de la metafísica: saber más es saber menos y viceversa. El intelligere -el noein- originario no es un bloque simple. Ab origine es una dialéctica donde centro y periferia son funciones necesarias de cumplimiento aleatorio y cuyos distanciamientos son variables entre sí, como también lo son respecto a la existencia histórica. De tal manera la obra de arte certifica la experiencia de que el saber actual se construye (poiesis) a partir de conceptos que ignoro: entiendo a partir de "entendedores ignotos", de conceptos plenos pero aun no sabidos, no unificados en y como la conciencia para la cual es la significación (pues ella es la significancia). La obra condensa, en el final del significado, esos "entendedores" que aun no sé pero que no obstante sé desde que los dejo actuar. Las fórmulas "más-ensignificado" y "significado in-significante" aluden a ellos, o mejor: al "entendedor ignoto" por excelencia: el tiempo, con su desnivel trascendental: concepto sin conciencia/existencia pre-concepto.

En relación con lo señalado es menester tener en cuenta que ahora nuestro discurso toca el débil -insignificante- pero inamovible fundamento inconcuso del pensar artístico-filosófico pre-permutante: respuesta ignota a la ocasional finitud del tiempo existencial y de la apertura en la que se lo piensa. En efecto, a diferencia del concepto -de la conciencia obstantivada para sí-, lo sabido mismo -el objeto- depende, para ser sabido, del significante. Ahora bien: ¿cómo sé que el significado excede al significante, si por definición se corresponden entre sí? Porque de algún 
modo el significado hace notar al significante, lo pone de manifiesto, lo abre. Si la ocasionalidad afecta a toda la obra, y si la in-significancia es un atributo negativo del significado, la apertura ocurre en la diferencia del significado, adecuada a él, que así acaba la profundización especulativa en la otra orilla, por decirlo así. Todo módulo de desorden quiebra aquella unión presuntamente tranquila. Signo perfecto es aquél en el cual significante y significado se unifican de tal cabal modo que no sólo es imposible separarlos, sino que tampoco se puede seguir ni imaginar su línea de separación. En la significancia artística, y más aun en la filosófica, tal perfección no pasa de ser un desiderátum, habida cuenta de la pluralidad de planos estructurales de significante y significado -cada uno de los cuales es un universo diferenciado en sí, teóricamente unificable sólo a la manera de lo que Hegel llama proposición especulativa- y de las complicaciones de sus dialécticas poiéticas. Ambos rostros luchan entre ellos a fin de que el otro no sea sino el cumplido ser del uno. De rebote el otro hace resaltar así la imperfección del uno, que a su vez le ilumina sus imperfecciones. Cabe subrayar que el significante se pone en evidencia de esta manera, así como ocurre cuando alguien se hace notar por no hallarse a la altura de lo que se espera de él. En vez de consumar el significado, hace visible el abismo de su íntima apertura, que ser-para-el-otro (el concepto) es una ignorada profundidad autoincrementante. En tal momento el significado es insignificante, con lo que se refuerza la segunda paradoja y se estatuye la tercera -tanto mayor es el saber cuanto más se ignora como saber-, paradoja que, en estrictos términos de significancia, dice que cuanto más se significa, menos significado es un significado.

Hacer visibles estos fenómenos es un modo de filosofar. Puede, pues, decirse que la filosofía consiste en la libre interrogación a fenómenos de significancia, uno de cuyos privilegiados campos de manifestación es la obra de arte. Dicho de otro modo: es la existencia histórica del tiempo, con su desnivel trascendental (es negándose -absoluto- y, en cuanto tal, es antítesis de absoluto). Por eso también se extrema en ocasionalidad, apertura e in-significancia. La ocasionalidad es la primera paradoja: la necesidad necesita lo aleatorio. No se puede excluir el azar porque, de otro modo, la necesidad es absurda. Su apertura es la segunda paradoja: lo cercano necesita lo lejano. No se puede excluir lo imposible creíble (Novalis), aunque sea increíble. Su in-significancia es la tercera paradoja: el más-en-significado es in-significante. Lo positivo necesita a lo negativo, el ser al no-ser, y viceversa. La metafísica permuta arte en filosofía, y viceversa, merced a las 
paradojas que radicalizan la significancia artística en la (retro) epifanía del tiempo.

La filosofía es, por lo tanto, conciencia inmanente de la obra de arte. Está dentro de ella como el aire dentro del organismo que respira. Por lo que acaba de indicarse, se ve que puede ser conciencia interna o externa. En principio toda conciencia es interna. La define la interioridad: su ser no es distinto del ser cuyo interior constituye. La filosofía es, pues, interior al arte en modo intencional-negativo, propio de toda conciencia respecto de aquello que ilumina y entifica en cuanto tal. Caso ejemplar de esta conciencia: el intérprete, en cuanto tal, es la conciencia interna de la obra musical, por lo que puede hablarse de una conciencia Landowska de Bach o una conciencia Furtwängler de Beethoven.

También la conciencia es externa a aquello cuyo ser (interior) le es en principio ajeno, ante todo porque nada es conciencia, salvo ella misma y, en forma correlativa, porque toda conciencia, por no ser ningún ente, se asegura la potencial conciencialidad de todo. En este sentido la filosofía es exterior al arte. La fusión de ambas significancias no pasa por eso de ser un artificio excepcional, en el caso rarísimo de que sea logrado. La tematización de Leonardo por Valéry puede sugerir esa conciencialidad.

En todo caso, parece razonable admitir que se considere a la filosofía como conciencia interior y exterior del arte. De ambas, la más significativa es la primera, en especial porque se nutre directamente del saber de la ocasionalidad, la apertura y la in-significancia. La permutación artefilosofía es, por ende, en primer lugar, interior a la obra de arte (ésta es locus nascendi de la metafísica), en tanto trascendental-analíticamente arte y filosofía son sistemas colindantes. En ninguno de ambos casos, menos aun en el primero, dicho vínculo es reversible. El arte puede ser organon de la filosofía (Schelling) pero no se dice así que puede ser su conciencia, si a esta se la toma en su sentido pleno como espacio-de-juego-de-tiempo del ser del ente. Si por eso la filosofía es autoconciencia de la conciencia interna del arte, éste no es sino conciencia retrospectiva del concepto, retroconciencia de la filosofía, tiempo-contratiempo que precipita a ésta a la gravidez sensorial de un pasado no sublimado en el presente secundario del concepto; en suma: cuya función es esencialmente deconstructiva.

Se puede, por consiguiente, sostener que ocasionalidad, apertura e in-significancia instauran la conciencia interna del arte como autoconciencia de la construcción de posibilidades matrices del concepto, del tiempo pensable y cognoscible. 


\section{Bibliografía}

Albizu E., Verdades del arte, Baudino/UNSAM, Buenos Aires, 2000.

Eco U., Obra Abierta (orig. Opera Aperta), Planeta/Agostini, Barcelona, 1984. (OA)

Gadamer H.-G., Wabrbeit und Methode, Mohr, Tübingen ${ }^{2}$, 1965. (WM)

Guerrero L.J., Estética operatoria en sus tres direcciones, Buenos Aires, Losada, 1956-67, 3 vol.

Heidegger M., Sein und Zeit, Niemeyer, Tübingen ${ }^{10}$, 1963. (SZ)

Kant I., Kritik der Urteilskraft, ed. Windelband (Akademie Ausgabe), Vorländer (Philosophische Bibliothek), Weischedel (Wissenschaftliche Buchgesellschft). (KU)

Marx K., Die heilige Familie, en Marx Die Frühschriften, ed. Landshut, Stuttgart, (Kröner), 1953.

Rescher N., Los limites de la ciencia (orig. The Limits of Science), Tecnos, Madrid, 1994.

\section{Resumen}

El estudio busca señalar cómo, en la situación espiritual de nuestro presente, arte y filosofía se acercan con frecuencia de tal manera que parece imposible delimitar con precisión uno de otro dominio. Dicha situación es particularmente crítica por cuanto, en nuestro presente, la filosofía mengua a ojos vista en tanto el arte se encuentra también vulnerado en su centro significante. El presente ensayo busca la vía de acceso a las patologías del arte y de la filosofía, que las acercan a transformaciones esenciales. Dichas vías de acceso son fenómenos marginales respecto del núcleo sancionado de la conciencia estética: ocasionalidad (Gadamer), apertura (Eco) e in-significancia (Guerrero y el autor de este trabajo. Así diseccionado el problema de los modos de interpenetración de arte y filosofía, se muestra que aquí es esencialmente conciencia interna de ésta.

\section{Abstract}

This study seeks to indicate how, in the spiritual situation of our present, art and philosophy often approach in such a way that it seems to be impossible to delimit one from another domains accurately. This situation is particularly critical since in 
our present, philosophy diminishes while art is also vulnerable in its significant centre. The present essay intends to find the route of access to the pathologies of art and philosophy, which brings them over to essential transformations. The above mentioned access roads are marginal phenomena respect to the sanctioned nucleus of the aesthetic conscience: ocassionality (Gadamer), opening (Eco) and insignificance (Guerrero and the author of this work). The art and philosophy ways of interpenetration problem, as we have analised, is essentially shown as internal conscience of the philosophy. 